\title{
A Preliminary Model for Conceptualizing the Contemporary Living Arrangements of Older Adults
}

\author{
Mackenzie Martin, BSc, BEd \\ Department of Social Policy and Intervention, University of Oxford, Oxford, England \\ Corresponding author: mmm2@ualberta.ca
}

\section{ABSTRACT}

The living arrangements of older adults are currently being impacted in multiple ways and are thus complex to study. Using the results of a rapid review of the 2000-2017 literature, the primary objective of this paper is to develop a conceptual model of older adults' living arrangements worldwide. Such a model is an important step in teasing out which elements of older adults' living arrangements influence various aspects of their health and well-being. This paper describes a preliminary model which conceptualizes older adults' living arrangements as inclusive of a multiplicity of factors in older adults' intimate, immediate, and broader settings. While this model is a start, there is considerable work left to be done to finalize the model before it is representative of older adults' living arrangements worldwide.

\section{Background}

Population aging is a well-established phenomenon. According to the United Nations (2007), the majority of people can now expect to live significantly longer than a generation ago ( $p$. iii). Further, the world's population is expected to continue aging - and in significant numbers. It is predicted that by the middle of the twenty-first century, the number of older adults globally will reach two billion (United Nations, 2007, p. iii). As a result, understanding and addressing the health and well-being of the globe's aging population will be a critical challenge of the twenty-first century (World Health Organization, 2011). Of course, there are many factors that contribute to and impact older adults' health (World Health Organization, n.d.) - one such factor being their living arrangements (Davis, Moritz, Nehaus, Barclay, \& Gee, 1997; Michael, Berman, Colditz, \& Kawachi, 2001; Organization for Economic Co-operation and Development, 2002; Sarwari, Fredman, Langenberg, \& Magaziner, 1998). Thus, an understanding of the living arrangements of older adults and how these living arrangements influence the health of older adults is increasingly relevant.

Studying people's living arrangements is complex because they are interconnected with phenomena such as urbanization and changes 
in families. Despite this complexity, it is critical that the arrangements in which older adults are living around the globe are documented so that governments, health providers, organizations, and others can support older adults to maximize their health and well-being. Knowledge of where, how, and with whom older adults are living is an important initial step in understanding the specific elements of living arrangements that impact older adults' health and well-being.

As a rapid review of the academic literature from January 2000 to May 2017 concluded that there is no comprehensive classification system describing the current living arrangements of older adults worldwide, a preliminary model was developed based on the literature. This paper details the research design and method used in the rapid review and utilizes the findings from the review to support the development of a preliminary model. The model, together with further research and refinement, could eventually form the basis of a classification system to categorize older adults living arrangements and link the various types of living arrangements with health outcomes.

\section{Design and Method}

Definitions

Older Adult

This paper does not limit the definition of older adult to any specific age range. The literature reveals that there is considerable global variation in terms of the age at which a person is considered to be an older adult. In this regard, regional variations and contextual factors play a role. That is, the life expectancy in a region may impact how older adult is defined in that region. For example, in studies focusing on Africa, older adult was defined as age 50 and above (McKinnon, Harper, \& Moore, 2013; Schatz, Madhaven, Collinson, Gomez-Olive, \& Ralston, 2015; Ssengonzi, 2009). Further, people in certain types of living or working environments may experience accelerated aging. For example, in an article by Wangmo, Handtke, Bretschneider, and Elger (2017) focusing on older prisoners, older adult was defined as age 50 and above. Thus, not limiting the definition of older adult in this paper is inclusive.

\section{Living Arrangement}

From an examination of the literature, there does not appear to be any common definition of living arrangement utilized by researchers. Generally speaking, however, one's living arrangement has been viewed as the physical unit of space, such as a condominium or bungalow, which one habitually occupies alone or with others. In contrast, this paper proposes that a broader and more expansive definition of living arrangements would be more accurate and useful to understand the contexts in which older adults are living.

\section{Rapid Review Rationale}

Of the many types of literature searches, the rapid review was determined to be most appropriate to ascertain the key themes in the literature from which to develop a preliminary model. According to Grant and Booth (2009), the rapid review method utilizes the key components of the systematic review to: determine what is already known in a body of literature, establish a sense of the quantity of literature available, develop themes and narratives from the existing body of literature, determine the overall direction of the literature findings, and briefly elaborate upon the quality of the articles (p. 95). Using this method allows reviewers to put carefully selected limits on a well-defined topic and reach key findings, while utilizing the rigor of the systematic review (Grant \& Booth, 2009).

\section{Search Strategy}

To develop a search strategy with the necessary search sensitivity and specificity, relevant grey 
and academic literature about older adults' living arrangements were analyzed to generate search terms. Following this research, the following search strategy was developed:

(living arrangement* or residence or coresidence or coresidence or residential arrangement* or household structure or housing or living environment)

AND

(older* or elderly or elder* or senior*).

Inclusion and Exclusion Criteria

Following the development and refinement of the search strategy, four exclusion criteria were chosen. First, the search was limited to the English language. Second, a date range from January 1, 2000 to May 1, 2017 was used to attempt to find contemporary information. Third, the search was limited to peer-reviewed journal articles. Fourth, the search strategy was only applied to document titles. Studies were included based on the inclusion criteria outlined in a data collection form developed by a team of researchers at an international non-governmental health organization. In sum, the form specified criteria for selecting articles that document the living arrangements of older adults worldwide. Using the strategy and aforementioned criteria, Sociological Abstracts, Family Studies Abstracts, Psyclnfo, PubMed, Global Health, and Urban Studies Abstracts were searched.

\section{Rapid Review Implementation}

Over two months in the summer of 2017 , the data collection form was used to conduct the rapid review. Once the articles found in the search were compiled, 346 articles remained following duplicate removal. From there, the title of each article was examined for evidence that the article met the inclusion criteria. To be included, the title of the article needed to clearly indicate that the living arrangements of older adults was a central focus of the article. This analysis reduced the number of articles to 122 . The abstracts of these articles were then analyzed for relevance and 91 articles were identified for detailed review. As the articles were read, detailed notes were taken about the studies' region(s) of study, who older adults are living with, and how older adults' living arrangements are classified. After reading and analyzing the articles, two more articles were removed from the review as the living arrangements of older adults was not a central focus, leaving 89 articles in the review.

\section{Results}

Region of Study

The studies generally delved into the living arrangements of older adults using data from a particular country or region of the world. Over the date range selected, the articles focused their attention as set out in Figure 1.

\section{Breakdown of Living Arrangements}

The results of the rapid review reveal that studies frequently focused on the living arrangements of older adults in institutional living settings (such as nursing homes or other facility-based living) or community living settings (such as privately owned or rented residences). The studies also focused on older adults living alone, with only a spouse, with adult children, or with others. The literature indicated that the majority of older adults are living with at least one other person.

\section{Living alone}

The living alone arrangement is a significant focus in the literature. The concept usually referred to an older adult being the only person inhabiting a dwelling, unit, or space (living unit). Occasionally, 


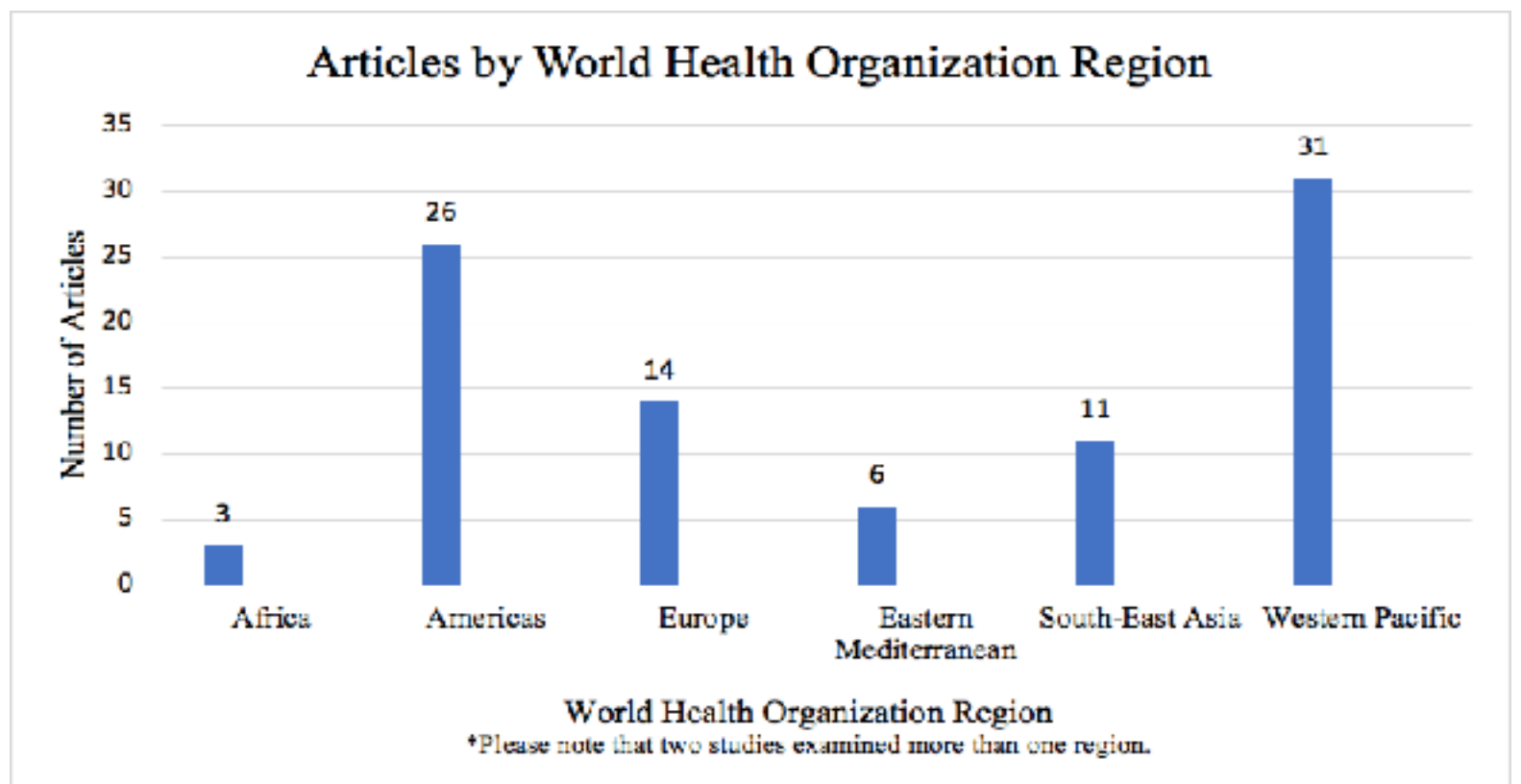

Figure 1: Review Articles by WHO Region (World Health Organization, n.d.)

the articles included living with a spouse in the living alone category. In general, the articles agreed that the frequency of living alone is on the rise. However, articles indicated that living alone is more common among certain groups of older adults - those with either higher or lower socioeconomic status (see Chaudhuri \& Roy, 2009; Henning-Smith, 2016; Kaida, Moyser, \& Park, 2009; Oh et al., 2015; Sereny, 2011) and those with more education (see Bolina \& Tavares, 2016; Gurak \& Krutz, 2010; Trujillo, Mroz, \& Angeles, 2007). In particular, a number of articles concluded that older adults who have higher socioeconomic status and/or more education and live alone "purchase privacy" (Mehio-Sibai, Beydoun, \& Tohme, 2009, p. 4). Despite this finding, many articles found that living alone was frequently correlated with negative health and well-being for older adults, especially for women (see Agrawal, 2012). Articles attributed the feminization of the negative impacts of living alone to women's longevity and the associated trend of more women being widowed. The negative health and well-being outcomes associated with living alone included suicidal ideation (see Kim, Lee, \& Lee, 2016), depressive symptoms (see Chan, Malhotra, Malhotra, \& Ostbye, 2011; Oh et al., 2015), chronic conditions (see Leung et al., 2016), disability (see Chaudhuri \& Roy, 2009; Dubuc et al., 2014), and increased loneliness (Gierveld, Dykstra, \& Schenk, 2012; Ng \& Northcott, 2015).

Co-residence with adult children

Similarly, a significant number of articles in the review put considerable emphasis on older adults' co-residence with their (never married, unmarried, and ever married) adult children. This is likely because the literature suggested that co-residence with adult children represents a significant percentage of the living arrangements of older adults worldwide (see Chan et al., 2011; Golandaj et al., 2015; McKinnon et al., 2013; Mehio-Sibai, Beydoun, \& Tohme, 2009), especially outside of Europe and the Americas. In these two regions (as defined by the WHO), co-residence with adult children was most common among immigrant populations (see Burr et al., 2012; 
Burr \& Mutchler, 2012). This living arrangement was largely defined as an older adult living with at least one adult child (see Burr et al., 2012). In some cases, this type of living arrangement also included the older adult's spouse (see Lau \& Kirby, 2009; Samanta, Chen, \& Vanneman, 2014). Of the various types of co-residence, the articles in the literature often prioritized studying older adults co-residence with a married child. The articles concluded that older adults in this arrangement were more likely to have lost their spouse (see Golandaj et al., 2015; Korinek, Zimmer, \& Gu, 2011), have fewer resources (see Gurak \& Kritz, 2010; Shideed, Sibai, \& Tohme, 2013), have more children (see Panigrahi, 2010; Shideed et al., 2013; Takagi, Silverstein, \& Crimmins, 2007), and have more physical decline and/or disability over the period studied (see Chaudhuri \& Roy, 2009; Korinek et al., 2011; Takagiet al., 2007). Overall, the impact of living with adult children seems inconclusive as it appears as though other factors within the living arrangement such as the presence of a spouse, household headship, and living arrangement concordance contribute significantly to older adults' experience (see Samanta et al., 2014; Schatz et al., 2015; Sereny, 2011; Sereny \& Gu, 2011; Takagi \& Silverstein, 2011).

\section{Discussion}

\section{Addressing Diversity}

Generally speaking, the articles considered two broad categories (institutional and community living) and four classes (alone, only spouse, adult children, other) of living arrangements. However, a minority of articles revealed that older adults live in a diversity of living arrangements including in tribal communities, in prisons, in near and virtual co-residence arrangements, on the street, and with domestic workers, sibling(s), and "orphans and vulnerable children" (Ssengonzi, 2009) not captured by the dominant categories frequently utilized in the literature. All of older adults' living arrangements need to be accounted for in a classification of living arrangements - a classification system that does justice to the heterogeneity of aging populations (World Health Organization, 2015b, p. 18). In fact, forcing the diversity and complexity of aging populations and their living arrangements into a few broad classes could be interpreted as ageist as it would appear to assume that older adults do not live in the vast array and complexity of arrangements in which other people reside (World Health Organization, 2015b, p. 168). Further, by forcing the plurality of older adults' living arrangements into a few broad categories and classes, the complexity of these arrangements is not accounted for and could possibly hinder the search to identify the living arrangements that have a significant impact on older adults' health and well-being. Any classification model of living arrangements must reflect the diversity, complexity, and evolution of older adults' living arrangements.

\section{Defining 'Living Arrangement'}

The literature appears to have a somewhat narrow view of what constitutes a living arrangement. For instance, the environment and relationships contiguous to an older adult's living unit do not appear to be considered to be a part of the older adult's living arrangement. Mainly, the literature seems to consider the elements and relationships inside an older adult's living unit to be part of his or her living arrangement - except when an older adult is living in an institution. Yet, an elderly woman estranged from her family and living by herself in a bungalow in a city where all her friends have died is surely in a very different living arrangement than an elderly woman living in a small town inhabited by friends and in a bungalow by herself next door to her adult daughter, son-in-law, and three grandchildren with whom she has a warm and supportive relationship. It defies logic that the two women's living arrangements are considered to be the same because living arrangement is limited 
to the fact that both women live by themselves in their own stand-alone living unit. Thus, the definition of living arrangement needs to capture more than the unit of space the older person lives in, who lives in the living unit, and whether the unit is in the community or an institution. Moving forward, there is need to conceptualize of the living arrangement as inclusive of the context inside the older adult's living unit, immediately outside the older adult's living unit, and in the broader context in which the older adult lives.

\section{Preliminary Model}

A preliminary model of living arrangements, rooted in the rapid review findings and based on a broader definition of what constitutes a living arrangement, has been developed (see Figure 2). The model suggests a number of factors that differentiate between classes of living arrangements.

The preliminary model depicts the older adult in the center of three concentric rings. Each of the three rings represents one part of an older adult's living arrangement; the farther the ring is from the center (the older adult), the farther the physical proximity of that part of the living arrangement from the older adult. The three rings comprising the living arrangement are the older adult's intimate setting (inside his or her living unit), contiguous setting (immediately surrounding his or her living unit), and broader setting (beyond the immediate setting). Each of the three settings of the living arrangement are influenced by a number of factors drawn from the literature.

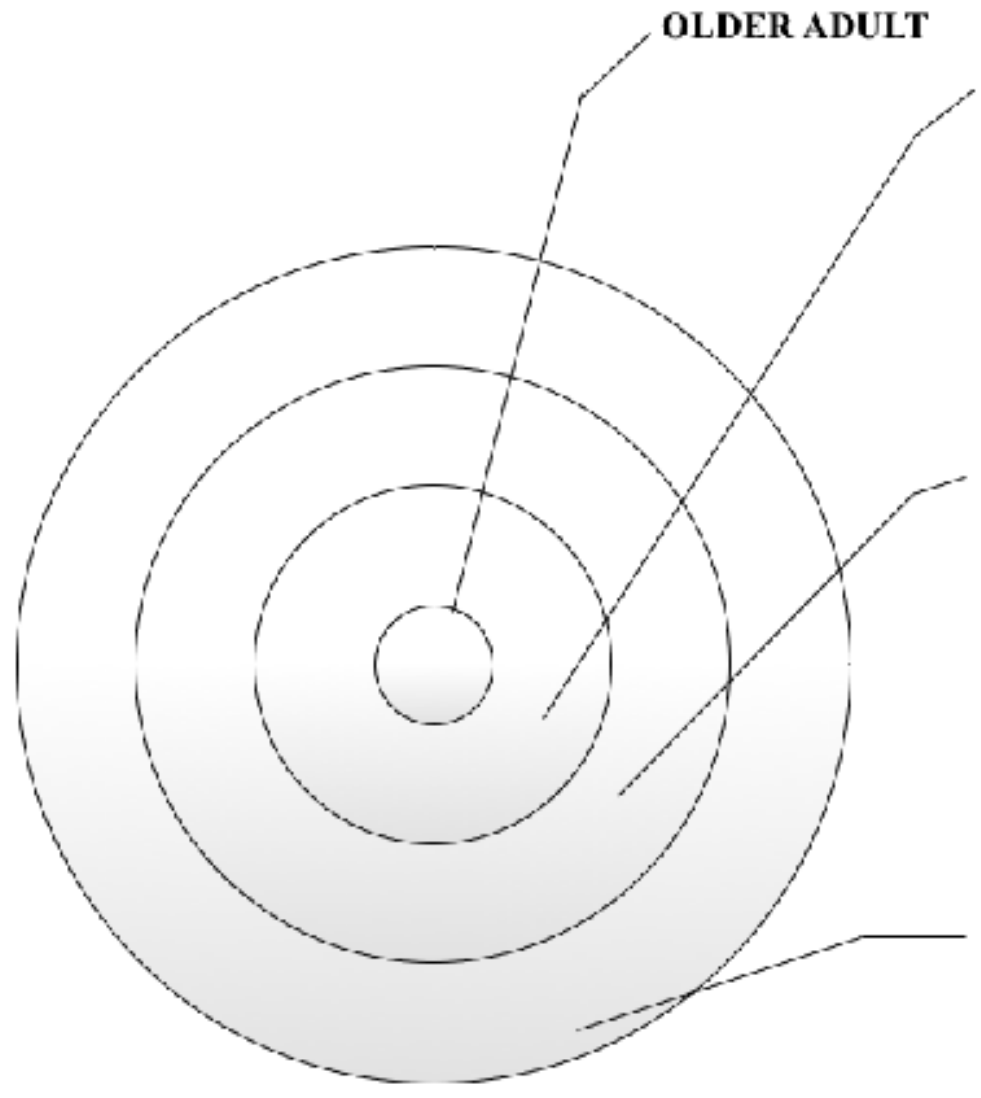

\section{LIVING UNIT}

- number of people in the unit - rclationship of poople in the unit to the older adult

- relationship dynamies

- ra ionale for living unil arangement

- timing flength of living unit arangement and perive in older adult's lite course)

\section{IMMEDIATE} SETTING OF LIVING UNIT

- number of units in a setting - relatiunship uf people in the setting to the olde: adult -networked or non-networked - rationale for living unit arrengement

- timing flength of living unit arringement and period in older aduld's life course

\section{BROADER SETTING OF LIVING UNIT}

-networked or non-networsed with community, relatives, and others in the envircnment vutside the contiguous selling

Figure 2 - Elements of an Older Adult's Living Arrangement 
Intimate Setting

The inner ring represents the intimate setting of the older adult's living unit (previously noted as including an older adult's dwelling, unit, or space). This is the setting in closest physical proximity to the older adult and is the setting in which the older adult is immersed. This setting is impacted by the number of people living in the unit, the relationship of the people in the unit to the older adult (the configuration), the dynamics of those relations, the rationale leading to the configuration, and timing factors (such as the length of the configuration and the period in the older adult's life course when the configuration exists).

The elements included in the intimate setting were derived from the literature's focus on living alone, living with a spouse, living with adult children, and living alone versus living with others. These foci suggest that the number of people in the living unit matters. The literature indicated that spouses, partners, friends, roommates, adult children, children (relatives and non-relatives), other adult relatives, tribal members, fellow prisoners, and domestic workers live with older adults. Although the literature's focus on some of these relationships was rare, the wide array of people who may be living with an older adult suggests that the types of relationships within the living unit are consequential. Extrapolating from the literature, the dynamics of those relationships are also important. For example, in the context of parent-child co-residence, a number of articles considered the consequences of power dynamics associated with household headship (see Bansod, 2009; Mehio-Sibai et al., 2009; Takagi \& Silverstein, 2011; Trujillo et al., 2007). Similarly, the rationale for living solo or together with one or more others in the unit is significant. For example, many articles looked at the role of limited economic resources, widowhood, disability, chronic disease, need for care, and physical decline to explain why older adults live with certain people. In conjunction, the literature sometimes discussed timing factors like the length of time during which people lived together in a unit. This was particularly the case in the context of coresidence with adult children. For instance, some articles distinguished between parent-child coresidence based on whether the living arrangement was lifelong - or "non-empty nest" (Sun, Lucas, Meng, \& Zhang, 2011) - or boomerang co-residence wherein children move back into their parents' home (Takagi et al., 2007; Takagi \& Silverstein, 2011). Taken together, these details constitute the complex mix of factors that make up the intimate setting of older adults' living arrangements.

\section{Contiguous Setting}

The middle ring represents the setting in which the living unit exists or the setting in closest physical proximity to the older adult's living unit. In this ring, the different types of arrangements depend on whether the living unit is stand-alone like a bungalow, in a complex of units like in a condo or assisted living site, or in a collective space such as a tribal community. The type of arrangement is further influenced by the number of living units in the structure, campus, or collection (structure); the connections, if any, between people in the structure and the older adult; the rationale for the older adult being situated there; and timing factors (such as the period in the older adult's life course when the older adult is situated there).

These factors were derived from the literature's discussion of older adults embedded in group environments such as seniorco-housing where older adults have their own living units and have access to meals, activities, services, and communal space (see Glass, 2012; Jolanki \& Vilkko, 2015; Pedersen, 2015). Other examples of group living settings include assisted living facilities (see Jonsdottir, Jonsson, Sigurdard, \& Ottir, 2015; Taylor \& Neill, 2009), prisons (Wangmo et al., 2017), extended stay hotels (see Lewinson \& Morgan, 2014), and 
tribal communities (Maruthakutti, 2011). Many of the studies of group living discussed the experiences of older adults in these environments. Frequently, older adults' connections with other individuals in the environment were elaborated upon, intimating that these connections were significant. For example, in an article by Jolanki and Vilkko (2015), the authors elaborate on the feelings of community established through a senior co-housing living arrangement in Finland. The type of group living environment generally points to the reason(s) for the older adult living there; older adults live in prisons because of their sentences, in nursing homes because they are assessed as requiring care, in lowincome housing due to financial resources, and in assisted living because they require certain services. These variables demonstrate the array of factors comprising the sub-setting immediately surrounding the living unit.

\section{Broader setting}

The outside ring - the broader setting in which the older adult lives - includes the elements in farthest physical proximity from the older adult's living unit. In this ring, the different types of arrangements are largely dependent on whether the older adult is networked or non-networked (Gruijters, 2017) with those on their street, in their neighborhood, or in the communities to which they belong. Older adults who are networked have close and important relationships with others. An example of a networked arrangement is 'near coresidence' (Isengard \& Szydlik, 2012). In an article by Sereny (2011), the author examines older Chinese adults' preference for living near their adult children and found that "nearby, it can be easier to gain the benefits from having children without actual co-residence" (p. 192). In contrast, those who are non-networked are more isolated.

In sum, using a broad definition of living arrangements, the preliminary model strives to depict three contextual layers which together comprise an older adult's living arrangement. Each layer aims to capture factors associated with that portion of the setting that the literature indicated was significant. Admittedly, there is considerable work left to be done to finalize the model before it is representative of older adults' living arrangements.

\section{Limitations}

There are two notable limitations in this study. First, there are limitations resulting from the rapid review method and process. In particular, this type of review has the potential for bias (Grant \& Booth, 2009). To mitigate potential bias, reviewers are cautioned to report their process so as to be transparent about the manner of conducting the review (Grant \& Booth, 2009); this paper is an attempt in transparency. Further, the parameters of the rapid review confined the articles selected for review. This means that the findings may not be based on the full body of relevant literature between 2000-2017. Despite this, 89 articles was a sizable number to uncover and analyze in a rapid review. Along these same lines, the search strategy and exclusion criteria applied to the strategy may have been too narrow so the review may have failed to capture the full body of appropriate literature. For instance, limiting the search to English and certain databases likely excluded relevant articles.

Second, bias may have impacted the method and process. The reviewer attempted to address this bias by utilizing a clear data abstraction form created in consultation with a team and frequently meeting with supervisors. Despite these limitations, the review and model are intended to provide food for thought about how to conceptualize of older adults' living arrangements.

\section{Conclusion}

Promoting optimal health and well-being for individuals from one end of their life course to 
the other is the ambitious and worthy goal of many organizations, governments, policy makers, academics, and citizens. For instance, one of the United Nations' Sustainable Development Goals is to "ensure healthy lives and promote well-being for all at all ages" (United Nations, 2015, para. 1). Clearly, the arrangements in which people live impact their health and well-being (Organization for Economic Co-operation and Development, 2002, p. 21). In general, gerontologists and others study the various aspects of older adults environments in an attempt to tease out the specific elements that contribute to the decline, maintenance, and promotion of their health and well-being. Once identified, those elements of living arrangements linked to various outcomes can be used to influence education, policy, decision-making, and action at individual, community, national, and international levels.

In this paper, a broad and layered preliminary model of living arrangements is proposed. The model conceptualizes older adults' living arrangements as inclusive of the multiplicity of factors in older adults' intimate, immediate, and broader settings. The eventual creation of a model based on an improved and robust model of living arrangements is worth pursuing as it may help to distinguish between diverse living arrangements and the elements in those arrangements impacting the health and well-being of the world's aging populations.

\section{Acknowledgements}

This paper was written in the summer of 2017 when I was an undergraduate student at the University of Alberta. I thank Loic Garcon and Dr. Paul Ong at the World Health Organization for their supervision of this research.

\section{Conflict of Interest}

The author does not declare any conflict of interest.

\section{Funding}

No funding was provided for the completion of this article. 


\section{References}

Agrawal, S. (2012). Effect of living arrangement on the health status of elderly in India: Findings from a national cross sectional survey. Asian Population Studies, 8(1), 87-101. Retrieved from http://dx/ doi.org/10.1080/17441730.2012.646842.

Bansod, D. (2009). Living arrangement and its effect on health of elderly in rural Maharashtra. Indian Journal of Social Work, 70(1), 55-70.

Bolina, A., \& Tavares, D. (2016). Living arrangements of the elderly and the sociodemographic and health determinants: A longitudinal study. Revista Latino-Americana de Enfermagem, 24, 1-10. Retrieved from https://www-ncbi-nlm-nih-gov.login.ezproxy.library.ualberta.ca/pmc/articles/ PMC4990036/.

Burr, J., Lowenstein, A., Tavares, J., Coyle, C., Mutchler, J., Katz, R., \& Khatutsky, G. (2012). The living arrangements of older immigrants from the former Soviet Union: A comparison of Israel and the United States. Journal or Aging Studies, 26(4), 401-409. Retrieved from http://dx.doi. org/10.1016/i.jaging.2012.05.002.

Burr, J., \& Mutchler, J. (2012). Housing characteristics of older Asian Americans. Journal of CrossCultural Gerontology, 27(3), 217-237. Retrieved from http://dx.doi.org/10.1007/s10823-0129173-2.

Chan, A., Malhotra, C., Malhotra, R., \& Ostbye, T. (2011). Living arrangements, social networks and depressive symptoms among older men and women in Singapore. International Journal of Geriatric Psychiatry, 26(6), 630-639. Retrieved from http://dx.doi.org/10.1002/gps.2574.

Chaudhuri, A., \& Roy, K. (2009). Gender differences in living arrangements among older persons in India. Journal of Asian and African Studies, 44(3), 259-277. Retrieved from http://dx.doi. org/10.1177/0021909609102897.

Davis, M., Moritz, D., Nehaus, J., Barclay, J., \& Gee, L. (1997). Living arrangements, changes in living arrangements, and survival among community dwelling older adults. American Journal of Public Health, 87(3), 371-377. Retrieved from https://ajph.aphapublications.org/doi/abs/10.2105/ AJPH.87.3.371?keytype2=tf_ipsecsha\&ijkey=ef48cc2a9c4d1b9cd389cc1374a21f87babbfb36.

Dubuc, N., Dubois, M., Demers, L., Tourigny, A., Tousignant, M., Desrosiers, J., ... \& Raiche, M. (2014). Alternate housing models for older people with disabilities: Their clientele, structures and resources in relation to the quality of and satisfaction with care delivery. Ageing and Society, 34(9), 1575-1600. Retrieved from http://dx.doi.org/10.1017/S0144686X13000354.

Gierveld, J., Dykstra, P., \& Schenk, N. (2012). Living arrangements, intergenerational support types and older adult loneliness in Eastern and Western Europe. Demographic Research, 27, 167-200. Retrieved from http://dx.doi.org/10.4054/DemRes.2012.27.7.

Glass, A. (2012). Elder co-housing in the United States: Three case studies. Built Environment, 38(3), 345363.

Golandaj, J., Goli, S., \& Das, K. (2015). Living arrangements among older population and perceptions on old age assistance among adult population in India. International Journal of Sociology and Social Policy, 33(5-6), 367-379. Retrieved from http://dx.doi.org/10.1108/IJSSP-09-2012-0083.

Grant, M., \& Booth, A. (2009). A typology of reviews: An analysis of 14 review types and associated methodologies. Health Information and Libraries Journal, 26(2), 91-108. Retrieved from http:// dx.doi.org/10.1016/j.jaging.2012.05.002.

Gruijters, R. (2017). Family care-giving and living arrangements of functionally impaired elders in rural China. Ageing and Society, 37(3), 633-655. 
Gurak, D., \& Kritz, M. (2010). Elderly Asian and Hispanic foreign- and native-born living arrangements: Accounting for differences. Research on Aging, 32(5), 567-594. Retrieved from http://dx/doi. org/10.1177/0164027510377160.

Henning-Smith, C. (2016). Quality of life and psychological distress among older adults: The role of living arrangements. Journal of Applied Gerontology, 35(1), 39-61. Retrieved from http://dx.doi. org/10.1177/0733464814530805.

Isengard, I., \& Szydlik, M. (2012). Living apart (or) together? Coresidence of elderly parents and their adult children in Europe. Research on Aging, 34(4), 449-474. Retrieved from http://dx.doi. org/10.1177/0164027511428455.

Jolanki, O., \& Vilkko, A. (2015). The meaning of a "sense of community" in a Finnish senior co-housing community. Journal of Housing for the Elderly, 29(1), 111-125. Retrieved from http://dx.doi.org/10. 1080/02763893.2015.989767.

Jonsdottir, S., Jonsson, J., \& Sigurdardottir, S. (2015). Housing for older people in Iceland: Apartments and nursing homes. Journal of Housing for the Elderly, 29(1-2), 197-208. Retrieved from http:// dx.doi.org/10.1090/02763893.2015.989779.

Kaida, L., Moyser, M., \& Park, S. (2009). Cultural preferences and economic constraints: The living arrangements of elderly Canadians. Canadian Journal on Aging, 28(4), 303-313. Retrieved from http://dx.doi.org/10.1017/S0714980809990146.

Kim, J., Lee, Y., \& Lee, J. (2016). Living arrangements and suicidal ideation among the Korean older adults. Aging and Mental Health, 20(12), 1305-1313. Retrieved from http://dx.doi.org/10.1080/136 07863.2015.1078280.

Korinek, K., Zimmer, Z., \& Gu, D. (2011). Transitions in marital status and functional health and patterns of intergenerational coresidence among China's elderly population. The Journal of Gerontology: Series B: Psychological Sciences and Social Sciences, 66(2), 260-270. Retrieved from http:// dx.doi.org/10.1093/geronb/gbq107.

Krieger, J., \& Higgins, D. (2002). Housing and health: Time again for public health action. American Journal of Public Health, 92(5), 758-768. Retrieved from https://ajph.aphapublications.org/doi/ pdfplus/10.2105/AJPH.92.5.758.

Lau, D., \& Kirby, J. (2009). The relationship between living arrangement and preventive care use among community-dwelling elderly persons. American Journal of Public Health, 99(7), 1315-1321. Retrieved from http://dx.doi.org/10.2105/AJPH.2008.151142.

Leung, Y., SuatLay, T., MingBoon, C., Raman, P., Chang, L., \& Chan, A. (2016). Living arrangements, social networks and onset or progression of pain among older adults in Singapore. Geriatrics and Gerontology International, 16(6), 693-700. Retrieved from http://dx.doi.org/10.1111/ggi.12539.

Lewinson, T., \& Morgan, K. (2014). Living in extended-stay hotels: Older residents' perceptions of satisfying and stressful living conditions. Journal of Housing for the Elderly, 28(3), 243-267. Retrieved from http://dx.doi.org/1080/02763893.2014.899540.

Maruthakutti, R. (2011). Housing and social habitation of the elderly among the Kanis, a tribal community in Tamil Nadu, India. Journal of Sociology and Social Anthropology, 2(2), 119-124.

McKinnon, B., Harper, S., \& Moore, S. (2013). The relationship of living arrangements and depressive symptoms among older adults in Sub-Saharan Africa. BMC Public Health, 13(682),1-9. Retrieved from http://dx.doi.org/10.1186/1471-2458-13-682.

Mehio-Sibai, A., Beydoun, M., \& Tohme, R. (2009). Living arrangements of ever-married older Lebanese women: Is living with married children advantageous? Journal of Cross-Cultural Gerontology, 
24(1), 5-17. Retrieved from http://dx/doi.org/10.1007/s10823-008-9057-7.

Michael, Y., Berman, L., Colditz, G., \& Kawachi, I. (2001). Living arrangements, social integration, and change in functional health status. American Journal of Epidemiology, 153(2), 123-131. Retrieved from http://dx.doi.org/10.1093/aje/153.2.123.

Ng, C., \& Northcott, H. (2015). Living arrangements and loneliness of South Asian immigrant seniors in Edmonton, Canada. Ageing and Society, 35(3), 552-575. Retrieved from http://dx.doi.org/10.1017/ S0144686X13000913.

Oh, D., Park, J., Lee, H., Kim, S., Choi, B., \& Nam, J. (2015). Association between living arrangements and depressive symptoms among older women and men in South Korea. Social Psychiatry and Psychiatric Epidemiology, 50(1), 133-141. Retrieved from http://dx.doi.org/10.1007/s00127-0140904-2.

Organization for Economic Co-operation and Development. (2002). Getting older, getting poorer? A study of the earnings, pensions, assets and living arrangements of older people in nine countries. Retrieved from http://www.oecd-ilibrary.org/docserver/download/345816633534. pdf?expires $=1504215089 \& i d=i d \&$ accname $=$ guest $\&$ checksum $=$ C6CB1373FF1DB2BEAF 9C62C65B23DDDA

Panigrahi, A. (2010). Living arrangements preferences of elderly in Orissa, India. Institute for Social and Economic Change. Retrieved from http://www.isec.ac.in/WP\%20240\%20-\%20\%20Akshay\%20 Kumar\%20Panigrahi_2.pdf.

Pedersen, M. (2015). Senior co-housing communities in Denmark. Journal of Housing for the Elderly, 29(1), 126-145. Retrieved from http://dx.doi.org/10.1080/02763893.2015.989770.

Samanta, T., Chen, F., \& Vanneman, R. (2014). Living arrangements and health of older adults in India. The Journal of Gerontology: Series B: Psychological Sciences and Social Sciences, 70(6), 937-947. Retrieved from http://dx.doi.org/10.1093/geronb/gbu164.

Sarwari, A., Fredman, L., Langenberg, P., \& Magaziner, J. (1998). Prospective study on the relation between living arrangement and change in functional health status of elderly women. American Journal of Epidemiology, 147(4), 370-378. Retrieved from http://dx.doi.org/oxfordjournals.aje. a009459.

Schatz, E., Madhaven, S., Collinson, M., Gomez-Olive, F., \& Ralston, M. (2015). Dependent or productive? A new approach to understanding the social positioning of older South Africans through living arrangements. Research on Aging, 37(6), 581-605. Retrieved from http://dx.doi. org/10.1177/0164027514545976.

Sereny, M., \& Gu, D. (2011). Living arrangement concordance and its association with self-rated health among institutionalized and community-residing older adults in China. Journal of Cross-Cultural Gerontology, 26(3), 239-259. Retrieved from http://dx.doi.org/10.1007/s10823-011-9145-y.

Sereny, M. (2011). Living arrangements of older adults in China: The interplay among preferences, realities, and health. Research on Aging, 33(2), 172-204. Retrieved from http://dx.doi. org/10.1177/0164027510392387.

Shideed, O., Sibai, A., \& Tohme, R. (2013). Living arrangements of older adults in Lebanon: Correlates of living with married children. Eastern Mediterranean Health Journal, 19(12), 1026-1034. Retrieved from http://applications.emro.who.int/emhj/v19/12/EMHJ_2013_19_12_1026_1034.pdf

Ssengonzi, R. (2009). The impact of HIV/AIDS on the living arrangements and well-being of elderly caregivers in rural Uganda. AIDS Care, 21(3), 309-314. Retrieved from http://dx.doi. org/10.1080/09540120802183461. 
Sun, X., Lucas, H., Meng, Q., \& Zhang, Y. (2011). Associations between living arrangements and healthrelated quality of life of urban elderly people: A study from China. Quality of Life Research, 20(3), 359-369. Retrieved from http://dx.doi.org/10.1007/s11136-010-9752-z.

Takagi, E., Silverstein, M., \& Crimmins, E. (2007). Intergenerational coresidence of older adults in Japan: Conditions for cultural plasticity. The Journals of Gerontology: Series B: Psychological Sciences and Social Sciences, 62(5), S330-S339. Retrieved from http://dx.doi.org/10.1093/ geronb/62.5.S330.

Takagi, E., \& Silverstein, M. (2011). Purchasing piety? Coresidence of married children with their older parents in Japan. Demography, 48(4), 1559-1579. Retrieved by http://dx.doi.org/10.1007/ s13524-011-0053-0.

Taylor, B., \& Neill, A. (2009). Sheltered housing and care for older people. Quality in Ageing, 10(4), 18-28. Retrieved from http://dx.doi.org/10.1108/14717794200900028

Trujillo, A., Mroz, T., \& Angeles, G. (2007). Living arrangements and the role of caregivers among the elderly in Latin America. World Health and Population, 9(2), 114-131. Retrieved from www. longwoods.com.

United Nations. Department of Economic and Social Affairs. (2007). World economic and social survey. Retrieved from http://www.un.org/en/development/desa/policy/wess/wess_ archive/2007wess.pdf.

United Nations. (2015). Sustainable development goals, goal 3. Retrieved from http://www.un.org/ sustainabledevelopment/health/\#.

Wangmo, T., Handtke, V., Bretschneider, W., \& Elger, B. (2017). Prisons should mirror society: The debate on age-segregated housing for older prisoners. Ageing and Society, 34(4), 675-694. Retrieved from http://dx.doi.org/10.1017/S0144686X15001373.

World Health Organization. (2011). Global health and aging. Retrieved from https://www.who.int/ ageing/publications/global_health.pdf.

World Health Organization. (2015a). Measuring the age-friendliness of cities: A guide to using the core indicators. Retrieved from http://apps.who.int/iris/ bitstream/10665/203830/1/9789241509695_eng.pdf?ua=1.

World Health Organization. (2015b). World report on ageing and health. Retrieved from http://apps. who.int/iris/bitstream/10665/186463/1/9789240694811_eng.pdf.

World Health Organization. (n.d.). Health impact assessment: The determinants of health. Retrieved from https://www.who.int/hia/evidence/doh/en/. 